\title{
O COLECCIONISMO CORPORATIVO EN GALICIA
}

Rosario Sarmiento

Xestora cultural e experta en coleccionismo 

A progresiva renovación cualitativa e cuantitativa que as artes plásticas tiveron en España desde comezos da década dos oitenta do pasado século foi, sen dúbida, unha resposta á necesidade do cambio cultural que a sociedade española demandaba tras a implantación da democracia. Segundo as palabras do historiador Francisco Calvo Serraller, dúas etapas diferenciadas van marcar estes cambios: a primeira, ata 1985, cunha "normalización social» da arte contemporánea; a segunda, a partir de mediados desa década, cun «franqueamento internacional» da nosa arte, ademais dun «aumento da información e cualificación dos criterios nos medios de comunicación de masas» ${ }^{1}$.

Ao mesmo tempo esta modernización plasmábase nunha progresiva creación de infraestruturas estables como museos e centros de arte contemporánea. Ao Museo Nacional Reina Sofía, creado en 1986 como un auténtico referente dunha modernidade na que cultura e arte contemporánea funcionaban como emblemas de modernización, seguíronlle centros como o IVAM (Instituto Valenciano de Arte Moderno), o CAAM (Centro Atlántico de Arte Moderno), ambos inaugurados en 1989, a Fundación Tàpies en 1990, o CGAC (Centro Galego de Arte Contemporánea) en 1993, o MACBA (Museo de Arte Contemporáneo de Barcelona) en 1995 ou o Museo Guggenheim en 1996. Nun segundo momento estaría o MARCO de Vigo (2002), o Museo Picasso de Málaga (2002), o MUSAC de León (2005) ou o TEA de Tenerife (2008), ata conformar por toda a xeografía española unha infraestrutura de espazos enfocados cara á arte contemporánea, o que contribuiría, xunto con outros factores, á súa normalización e difusión.

Estes centros xeradores de actividades expositivas e de difusión da arte contemporánea influíran en que estes mesmos anos coincidan cun incremento do coleccionismo corporativo, é dicir, de carácter institucional e empresarial, relacionado cunha dinamización do mercado artístico e consolidación do galerismo.

Baixo un carácter institucional e empresarial foron xurdindo as coleccións de entidades como o BBVA (1998), a Fundación La Caixa (1985), a Colección Arte Contemporánea (1987), grandes referentes do coleccionismo corporativo en España, a Fundación MAPFRE (1988), a Fundación Coca-Cola (1993) ou a Colección Museo Wurth (2005), entre outras.

«A creación de coleccións privadas é, se cadra, o acontecemento máis decisivo no noso país, mesmo cando se está pensando nese enriquecemento do noso futuro patrimonio oficial de arte contemporánea», aseguraba o historiador Francisco Calvo Serraller nunhas reflexións a propósito da creación da Colección ARCO, nas que fai fincapé nese papel tan necesario para o fomento da creatividade e o mercado da arte que debe exercer o coleccionismo. Porque público ou privado, respondendo a uns parámetros ou formas de actuación diferentes, o coleccionismo é un dos piares básicos para recrear a historia cultural dun país e das xeracións vindeiras.

Galicia viviu tamén desde comezos dos anos oitenta do pasado século un proceso de aceleración na difusión e posta en valor da arte contemporánea. A década inaugúrase coa irrupción dun nome, Atlántica, e con el un clima dinamizador que conecta coas inquietudes da contemporaneidade fóra de Galicia. Esta renovación estendeuse a ámbitos como a moda, o deseño, a literatura ou o audiovisual. Ao mesmo tempo, o impulso dado desde a esfera pública e privada plasmouse na organización de exposicións de arte española e internacional, como as diferentes edicións da Bienal de Pontevedra ou a Fotobienal de Vigo; bolsas e axudas para novos artistas como as convocadas polas deputacións, Unión Fenosa e fundacións, e tamén unha paulatina profesionalización do mundo galerístico, plasmada na organización de feiras de arte como o Foro Atlántico.

1 CALVO SERRALLER, F. (1996): «La política oficial y el arte contemporáneo entre 1980 y 1995 . Mercado del arte y coleccionismo en España (1989-1995)», Cuadernos ICO, n 9, pp. 67-80. 
A partir da década dos noventa, esta progresiva renovación cualitativa e cuantitativa das artes plásticas plásmase tamén na creación de infraestruturas culturais, museos e centros de arte contemporánea: Auditorio de Galicia (1989), Facultade de Belas Artes de Pontevedra (1990), Centro Galego de Arte Contemporánea (1993) ou MARCO (2002) irán parellos á posta en marcha de infraestruturas culturais como a Fundación Barrié (1995) e Museo Unión Fenosa (1995) na Coruña, as diferentes sedes da Fundación Caixa Galicia (2000, 2005, 2006), a Fundación Luís Seoane (2003), etc.

Todo isto contribuirá a ir conformando novas xeracións de artistas máis formadas e informadas, o acceso do público a exposicións de carácter internacional e a inclusión de Galicia dentro dos circuítos da arte contemporánea.

Ao mesmo tempo comeza a conformarse un novo coleccionismo de índole privada e empresarial que deu sentido a coleccións como a de Unión Fenosa (1989), Caixa Galicia (1996), Fundación Jove e Fundación Barrié (2008).

\section{COLECCIÓN AFUNDACIÓN (COLECCIÓN CAIXAVIGO, CAIXANOVA, NOVACAIXAGALICIA, AFUNDACIÓN). VIGO} www.afundación.org

Iníciase en 1960. Ten a súa orixe nos fondos artísticos da Obra Social da Caixa de Aforros de Vigo (é importante destacar o papel de personalidades como a de Ángel Ilarri na súa formación). Posteriormente convértese na colección Caixanova, ao engadir os fondos artísticos das caixas de Pontevedra e Ourense tras a fusión destas entidades. Despois da fusión de Caixa Galicia e Caixanova, e a súa conversión en Novacaixagalicia, pasou a denominarse así. A posterior transformación das caixas fusionadas en Novagalicia Banco fixo que quedase unida á Fundación Obra Social desta, actualmente Afundación.

- Composta por 5638 pezas (3486 obras artísticas e 2170 obra gráfica).

-Tipoloxía: Trátase dunha colección de arte galega dos séculos xIX e xx, conformada por pintura, escultura, fotografía, obra gráfica e instalación.

—Algúns autores significativos: Villaamil, Dionisio Fierros, Avendaño, Román Navarro, Joaquín Vaamonde, Llorens, Sotomayor, Sobrino, Castelao, Federico Ribas, Souto, Laxeiro, Maside, Colmeiro, Lugrís, Grandío, Pérez Bellas, Pailós, Patiño, Lamazares, Silverio Rivas, Pamen Pereira...

—Localización: Almacenada. Desde o ano 2003 unha pequena porcentaxe da colección está exposta de forma permanente no edificio Afundación en Vigo.

-Difusión: Exposicións temporais de fondos, publicación de catálogos. Algunhas referencias: Plástica gaIlega (Vigo, 1981), Artistas gallegos en la Colección C.A.M.V. (1986), Artistas galegos na Colección Caixavigo (Porto, 1989), Arte galega na Colección Caixavigo (Vigo, 1992), Colección Caixavigo: pintura, escultura, dibujo (Vigo, 1993), Colección Caixanova, unha visión da Arte Contemporánea Galega (Vigo, 2002), Artistas pontevedreses na colección Caixanova (Pontevedra, 2006), De nova materia: escultura contemporánea na colección Caixanova (Ourense, 2008).

-Política de préstamos: Museos, institucións, etc.

-Declaración BIC: Na liña de preservar os conxuntos artísticos das antigas caixas de aforros, o 23 de outubro de 2013 a Dirección Xeral de Patrimonio da Xunta de Galicia inicia o expediente de declaración BIC (ben de interese cultural) para a totalidade das 5638 obras que conforman a colección Afundación. Entre outros aspectos permite garantir a protección, conservación, difusión e accesibilidade ao público.

Dous anos despois, o 8 do outubro do 2015, a Xunta de Galicia declara BIC unha parte dos seus fondos, un total de 2533 obras de 485 artistas. Quedan excluídas as seguintes:

—Obras doadas á institución en contrapartida pola realización de exposicións, criterio mantido nos anos 70 e 80 do século $x$. 
-Obras inventariadas por seren presentadas ás edicións da Bienal Internacional de Gravado e que pertencen a artistas foráneos, sen relación con Galicia e sen obra representativa ou recoñecida.

-Obras adquiridas coa mera funcionalidade de servir de elementos ornamentais en espazos da entidade.

-Obras recentes das que non se dispón de información suficiente para establecer as súas condicións de catalogación.

\section{COLECCIÓN ABANCA (CAIXA GALICIA-NOVAGALICIA BANCO, ABANCA). A CORUÑA}

www.coleccion.abanca.com

Iníciase en 1996. Ten a súa orixe na Colección Caixa Galicia. Tras a fusión das antigas Caixanova e Caixagalicia e a súa conversión en Novacaixagalicia, esta traspasa o seu negocio financeiro a Novagalicia Banco, que é adquirido en 2013 polo grupo venezolano Banesco. É o seu actual propietario.

—Composta por 1343 obras de 239 artistas. É considerada a colección corporativa máis importante de Galicia.

-Tipoloxía: Colección de arte contemporánea do século xx e xxı. Pintura, escultura, debuxo, fotografía e instalación. Desde a súa orixe foi deseñada cuns criterios claros: unir o mundo empresarial e artístico con espírito de mecenado, dimensión de profesionalidade e vocación pedagóxica.

—Algúns autores significativos: Castelao, Colmeiro, Laxeiro, Seoane, Lugrís, Grandío, Maruja Mallo, Fernández Granell, Labra, A. Patiño, M. Lamas, Picasso, Miró, Leger, Dalí, Braque, Blanchard, Óscar Domínguez, W. Lam, Millares, Tàpies, Chillida, Saura, Gordillo, Barceló, Susana Solano, Xurxo Oro Claro, Juan Muñoz, Cristina Iglesias, Plensa, Sean Scully, Emiliano de Cavalcanti, José Pedro Croft, Julião Sarmento...

—Localización: A colección gárdase nun edificio de alta seguridade e tecnoloxía adecuada en canto a conservación, que conta ademais cun espazo de restauración.

—Difusión: Ampla difusión dos seus fondos con exposicións de carácter monográfico e temático: Francisco Lloréns (1997-1998), Tino Grandío e Isidoro Brocos (2003), Territorio de mulleres (2006-2007), Antonio Murado (2007-2008), O espello cotián (2007-2008), Viento del Oeste, viento del Este (2008), Leopoldo Nóvoa (2009), Miradas: Galicia hasta 1975, Desde el informalismo a lo multicolor, Hacia el paraíso y Realidades, expresiones, tramas (2009).

-Política de préstamos de obra: Museos e institucións nacionais e internacionais.

—Declaración BIC: 0 de 23 de outubro do 2013 a Dirección Xeral de Patrimonio da Xunta de Galicia inicia o expediente para a declaración de ben de interese cultural $(\mathrm{BIC})$ a totalidade das obras que conforman a colección de arte Novagalicia Banco. Finalmente é declarada BIC na totalidade dos seus fondos, o 8 de outubro de 2015.

$\mathrm{Na}$ instrución do expediente administrativo fica acreditado o carácter sobranceiro da colección, en especial pola calidade e representatividade da obra pictórica galega dos últimos 130 anos, o contraste con obras nacionais e estranxeiras da máxima calidade que colaboran na definición do seu discurso, así como o excelente estado de conservación, difusión e didáctica da colección.

\section{COLECCIÓN DE ARTE CONTEMPORÁNEO ESPAÑOL GAS NATURAL FENOSA (UNIÓN FENOSA, GAS NATURAL FENOSA). A CORUÑA}

www.fundaciongasnaturalfenosa.org/mac/

Iníciase en 1989 unida á creación da Mostra Unión Fenosa, que nace como unha bienal de pintura e escultura aberta a artistas galegos. En 1993, a Mostra adquiriu carácter nacional cun récord histórico de participación. En 1995 inaugurouse o Museo de Arte Contemporánea Gas Natural Fenosa. A Mostra foi desde a súa orixe o xerme desta colección.

En 2006, coincidindo coa súa novena edición, a Mostra pasou a ser internacional e a outorgar tres premios. As obras premiadas pasan a formar parte da Colección de Arte Contemporáneo Español de Gas Natural Fenosa. Con 
periodicidade bianual o MAC segue a convocar esta mostra co propósito de promover os novos valores da plástica, establecer un espazo para a arte e crear unha colección de arte contemporánea.

- Composta por 600 obras.

-Tipoloxía: Arte contemporánea século xx. Pintura, escultura, debuxo, fotografía e instalación.

—Algúns autores significativos: Alfonso Albacete, Mónica Alonso, Chema Alvargonzález, Manuel Ángeles Ortiz, Eduardo Arroyo, Elena Ansis, Miquel Barceló, Darío Basso, Bores, Joan Brossa, Berta Cáccamo, Carmen Calvo, Miguel Ángel Campano, Daniel Canogar, Vari Caramés, Xurxo Lobato, Luis Caruncho, Tony Catany, Martín Chirino, Óscar Domínguez, García Sevilla, Julio González, Dionisio González, Sofía Jack, Maruja Mallo, Lucio Muñoz, Antón Patiño, Manolo Paz, Guillermo Pérez Villalta, Alberto Sánchez, Adolfo Schlosser, Torres García, Soledad Sevilla, Paco Pestana...

—Localización: Atópase no edificio do Museo Gas Natural Fenosa MAC da Coruña, onde existe unha sala que exhibe de forma permanente unha selección de obras que son revisadas periodicamente.

—Difusión: Algunhas das exposicións realizadas son Colección de arte contemporáneo Unión Fenosa (2007), Identidad y ausencia. Figuraciones convulsas en la Colección Gas Natural Fenosa (2010), Colección de Arte Contemporáneo Español de Gas Natural Fenosa (2014).

\section{COLECCIÓN Ma JOSÉ JOVE. A CORUÑA}

Www.fundacionmariajosejove.org

Iníciase a finais da década dos noventa. A colección, cuxa titularidade pertence a Manuel Jove Capelán, é cedida con carácter temporal no ano 2005 á Fundación María José Jove.

- Composta ao redor de 600 obras.

-Tipoloxía: Arte contemporánea galega, española e internacional, desde finais do xIx ao xXı. Pintura, escultura, debuxo, fotografía e instalación.

—Algúns autores significativos: Pérez Villaamil, Mariano Fortuny, Mir, Casas, Nonell, Anglada Camarasa, Romero de Torres, Sotomayor, Francisco Bores, Óscar Domínguez, Salvador Dalí, Maruja Mallo, Eugenio Granell, Fernand Léger, Miró, Picasso, Castelao, Colmeiro, Saura, Millares, Feito, Arroyo, Saura, Viola, Feito, Rivera, Canogar, Carlos Alcolea, Luis Gordillo, Baselitz, Anselm Kiefer, Louise Bourgeois, Cristina Iglesias, Baltazar Torres, Mateo Maté, Elmgreen \& Dragset, Sofía Táboas...

—Localización: Das case 600 obras, expóñense de forma permanente arredor de 130, distribuídas nun espazo aproximado de $1000 \mathrm{~m}^{2}$. A exposición articúlase sobre 11 eixes temáticos relacionados con asuntos que foron obxecto de estudo recorrente na historia das artes visuais.

Conta cun espazo de almacén e restauración.

—Difusión: Algunhas exposicións dos seus fondos realizadas dentro e fóra de Galicia, como El espejo que huye, Palacio de Revilagigedo (2009), ¿Qué hace esto aquí? Arte contemporáneo de la Fundación María José Jove en el Museo Lázaro Galdiano (2012) ou No hablaremos de Picasso. Arte Contemporáneo Fundación María José Jove (2015).

Tamén realiza unha ampla política de préstamos de obra a museos e institucións.

\section{COLECCIÓN FUNDACIÓN BARRIÉ. A CORUÑA}

www.http://fundacionbarrie.org

Iníciase no ano 2008.

- Composta por 53 obras de 46 artistas. 
-Tipoloxía: Pintura contemporánea internacional, incluídos artistas que tamén desde a fotografía, a instalación ou a escultura se achegan á pintura e xogan coa expansión e a reencarnación da pintura noutros medios.

—Algúns autores significativos: Pedro Barbeito, Manuel Vilariño, Ángela de la Cruz, Suso Fandiño, Manuel Caeiro, Katharina Groose, Pedro Calapez, Helmut Dorner, Jean-Marc Bustamente...

—Localización: A Coruña. Non está exposta.

—Difusión: Exposicións dentro e fóra de Galicia, Colección de Pintura Contemporánea Internacional (2012), Exposición "LA COLECCIÓN" de la FUNDACIÓN BARRIÉ (2015). 